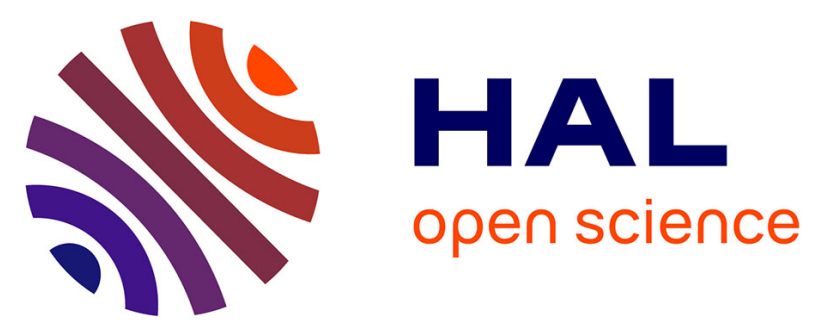

\title{
Two-Photon Absorption and Two-Photon Circular Dichroism of a Hexahelicene Derivative with a Terminal Donor-Phenyl-Acceptor Motif
}

Yuly Vesga, Carlos Diaz, Jeanne Crassous, Florencio E Hernandez

\section{- To cite this version:}

Yuly Vesga, Carlos Diaz, Jeanne Crassous, Florencio E Hernandez. Two-Photon Absorption and TwoPhoton Circular Dichroism of a Hexahelicene Derivative with a Terminal Donor-Phenyl-Acceptor Motif. Journal of Physical Chemistry A, 2018, 122 (13), pp.3365-3373. 10.1021/acs.jpca.8b00347. hal-01771522

HAL Id: hal-01771522

https://hal-univ-rennes1.archives-ouvertes.fr/hal-01771522

Submitted on 8 Jun 2018

HAL is a multi-disciplinary open access archive for the deposit and dissemination of scientific research documents, whether they are published or not. The documents may come from teaching and research institutions in France or abroad, or from public or private research centers.
L'archive ouverte pluridisciplinaire HAL, est destinée au dépôt et à la diffusion de documents scientifiques de niveau recherche, publiés ou non, émanant des établissements d'enseignement et de recherche français ou étrangers, des laboratoires publics ou privés. 


\title{
Two-Photon Absorption and Two-Photon Circular Dichroism of a Hexahelicene Derivative with a Terminal Donor-Phenyl-Acceptor Motif
}

\author{
Yuly Vesga, ${ }^{1}$ Carlos Diaz, ${ }^{1}$ Jeanne Crassous, ${ }^{3}$ Florencio E. Hernandez $1,2, *$ \\ ${ }^{1}$ Department of Chemistry and ${ }^{2}$ The College of Optics and Photonics, CREOL, University of Central Florida, P. O. \\ Box 162366, Orlando, Florida 32816-2366, USA \\ ${ }^{3}$ Sciences Chimiques de Rennes UMR 6226 CNRS, Universitè de Rennes 1, 35042 Rennes Cedex, France \\ *Corresponding Authors: florencio.hernandez@ucf.edu
}

\begin{abstract}
Herein, we report on the theoretical-experimental analysis of the two photon absorption and circular dichroism spectra of 1-(2-pyridyl)-4-methoxy-carbo[6]helicene derivative (P6). The primary outcomes of our investigation on this particular helicene derivative with a donor-acceptor motif on one end led to two important conclusions: 1) The lengthening of the $\pi$-electron delocalization within the helical core of $\mathbf{P 6}$ predominantly increases the contribution of the magnetic dipole transition moment to the TPCD signal; 2) The electric quadrupole transition moment contribution to the TPCD signal is enhanced by the intramolecular charge transfer (ICT) produced by the donor-acceptor combination on one end of the molecule. In order to corroborate our results, we performed a comparative theoretical analysis of the effect of the energy gap and ICT on TPCD on a series of P6-like helicenes with different donor-acceptor combinations. Twophoton absorption (TPA) and two-photon circular dichroism (TPCD) spectra were obtained using the double L-scan technique over a broad spectral range (400-900 nm) using $90 \mathrm{fs}$ pulses at a low repetition rate $(2-50 \mathrm{~Hz})$ produced by an amplified femtosecond system. The theoretical simulations were calculated using Time- Dependent Density Functional Theory (TD-DFT) at the CAM-B3LYP/6-311++G(d,p) level of theory.




\section{INTRODUCTION}

The interpretation of the high optical activity in helicenic systems and its combination with other properties like strong absorption and emission in the visible spectral range and redox activity ${ }^{1-3}$ has been the focus of investigation during the last twenty years. Chiral molecules such as helicenes are becoming more and more popular because of their direct application in asymmetric catalysis, ${ }^{4-}$ ${ }^{5}$ chiroptical switches, ${ }^{6}$ enantioselective fluorescence detectors, ${ }^{7}$ circularly polarized emitters for chiral OLEDs, ${ }^{8-9}$ and nonlinear optical (NLO) devices. ${ }^{10-11}$

Great efforts have been made in the development and application of two techniques, circular dichroism (CD) and optical rotatory dispersion (ORD). ${ }^{12} \mathrm{CD}$ is known as electronic circular dichroism (ECD) when linked to transitions between electronic states and it is expressed as the difference between left (LCPL) and right (RCPL) circularly polarized light of one-photon absorption. ${ }^{13-14}$ Although, ECD has been the most common technique for the analysis of conformational and physical-chemistry properties of optically active molecular systems, ${ }^{12}$ it presents significant challenges for their study in the UV region. ${ }^{15}$ Among the most predominant are: absorption from buffers and solvents in the same spectral region, as well as scattering enhancement from heterogeneous samples. These could result in the hindrance of the ECD signal at shorter wavelengths.

In order to circumvent aforementioned shortcomings of ECD, scientist in the field have proposed multiple linear $^{16-19}$ and non linear ${ }^{20-23}$ polarization dependent methods. The latter includes two-photon circular dichroism (TPCD), ${ }^{24}$ which is the nonlinear counterpart of ECD, i.e. the difference in two-photon absorption cross-sections obtained with LCPL and RCPL at a specific wavelength $\left(\triangle \delta^{T P C D}(\lambda)=\delta_{L}^{T P A}(\lambda)-\delta_{R}^{T P A}(\lambda)\right){ }^{25-27}$. Since typical excitation wavelengths in TPA are approximately two folds longer (degenerate case) than in OPA, negligible absorption at the 
excitation wavelength and minimization of scattering are observed. ${ }^{28-29}$ TPA is known for its intrinsic spatial resolution and penetration, ${ }^{29}$ as well as better background discrimination and reduced photodamage to living specimens. ${ }^{28}$ All these advantages combined with the characteristic sensitivity of TPCD to structural changes and accessibility to the far ultra violet (far-UV) ${ }^{30}$ make of this technique an excellent candidate for studying conformational and structural distortions of optically active chiral molecules in the far-UV.

The first experimental attempt to measure TPCD was made in 1995 by Richardson and coworkers, who used the fluorescence-detected two-photon circular dichroism (FD-TPCD) method. ${ }^{31}$ However, it was not until the advent of the double L-scan technique that full experimental TPCD spectra in optically active molecules were measured. ${ }^{32}$ Since then, TPCD became one of the best option for the structural study and conformational understanding of chiral molecules.

In the quest to increase the current understanding of the structure-property relationship of TPCD, we have been working on the theoretical-experimental analysis of the TPCD response in various molecular systems. ${ }^{24}$, 30, 33-37 With these investigations, we have nurtured our knowledge of TPCD in organic molecules. However, more systems need to be examined in order to fully explore this nonlinear optical property and its capability. In order to achieve this goal, herein, we present the theoretical-experimental analysis of the effect of pseudo-localized intramolecular charge transfer on the TPA and TPCD signal of a specific organic molecule with extended $\pi$ electron delocalization, helical chirality, and different donor-acceptor group combinations on one end. We first demonstrate that the lengthening of the $\pi$-electron delocalization within the helical core of $\mathbf{P 6}$ due to the presence of the pyridine moiety, predominantly increases the contribution of the magnetic dipole transition moment to the TPCD signal. This is explained by the observed 
decrease in the corresponding HOMO-LUMO energy gap and its direct correlation with the molecular angular momentum. Next, we show that the replacement of the pyridine moiety present in $\mathbf{P 6}$ by stronger electron withdrawing substituents (eWS) enhances the electron transfer towards eWS. This effect results in a higher electric quadrupole transition moment contribution to the TPCD signal.

\section{EXPERIMENTAL SECTION}

$P-(+)$ and $M-(-)$ enantiomers of 1-(2-pyridyl)-4-methoxy[6]helicene (P6) were synthesized according to a published procedure. ${ }^{38}$ Circular dichroism spectra (in $\mathrm{M}^{-1} \mathrm{~cm}^{-1}$ ) were measured on a Jasco J-815 Circular Dichroism Spectrometer (IFR140 facility - Université de Rennes 1) in dichloromethane and at concentrations around $5 \times 10^{-5} \mathrm{M}$.

OPA measurements were carried out in a single-beam spectrophotometer (Agilent 8453 Diode Array UV-Vis) from 190 to $600 \mathrm{~nm}$ in a $0.1 \mathrm{~cm}$ quartz cuvette in solutions with a concentration range from $2.0 \times 10^{-5}$ to $2.0 \times 10^{-4} \mathrm{M}$ in THF. ECD spectra were performed in a J-815 CD spectropolarimeter (Jasco Corp., Tokyo, Japan). Solutions were prepared at a concentration of $1.0 \times 10^{-5} \mathrm{M}$ in THF, at $25{ }^{\circ} \mathrm{C}$, and in a $4 \mathrm{~mm}$ quartz cuvette. The ECD spectral region scanned ranged from $190 \mathrm{~nm}$ to $600 \mathrm{~nm}$ with a $1 \mathrm{~nm}$ step and a scan speed of $50 \mathrm{~nm} / \mathrm{min}$.

TPA and TPCD experiments were completed by using the Double L-scan technique in solutions with concentration of $8.7 \times 10^{-2} \mathrm{M}$ in THF. Two-photon excitation was generated with a computer-controlled femtosecond optical parametric amplifier (OPerA Solo) pumped by an amplified laser system from COHERENT, Inc. The entire system is capable of generating $90 \mathrm{fs}$ (FWHM) pulses over a wavelength range from $240 \mathrm{~nm}$ to $2.6 \mu \mathrm{m}$, and pulse energies of up to 350 $\mu \mathrm{J}$. Measurements were done at a repetition rate ranging from 2 to $50 \mathrm{~Hz}$ to avoid any contribution 
from cumulative effects. The pulse width was measured by a single-shot autocorrelator from COHERENT, Inc. and a frequency-resolved optical gaiting (FROG) from Swamp Optics, LLC.

\section{COMPUTATIONAL METHODS}

The molecular structure of $M-(-)$ and $P$-(+)-P6 and the other donor-acceptor helicenes (Figure 1) were optimized using Density Functional Theory (DFT), ${ }^{39}$ with the Coulomb attenuating method-Becke's three-parameter exchange, Lee, Yang and Parr correlation (CAM-B3LYP) ${ }^{40}$ hybrid functional in combination with the 6-311++G(d,p $)^{41-42}$ basis set, employing Gaussian $09^{43}$. Solvent effects were taken into consideration through the polarizable continuum model (PCM) ${ }^{44}$

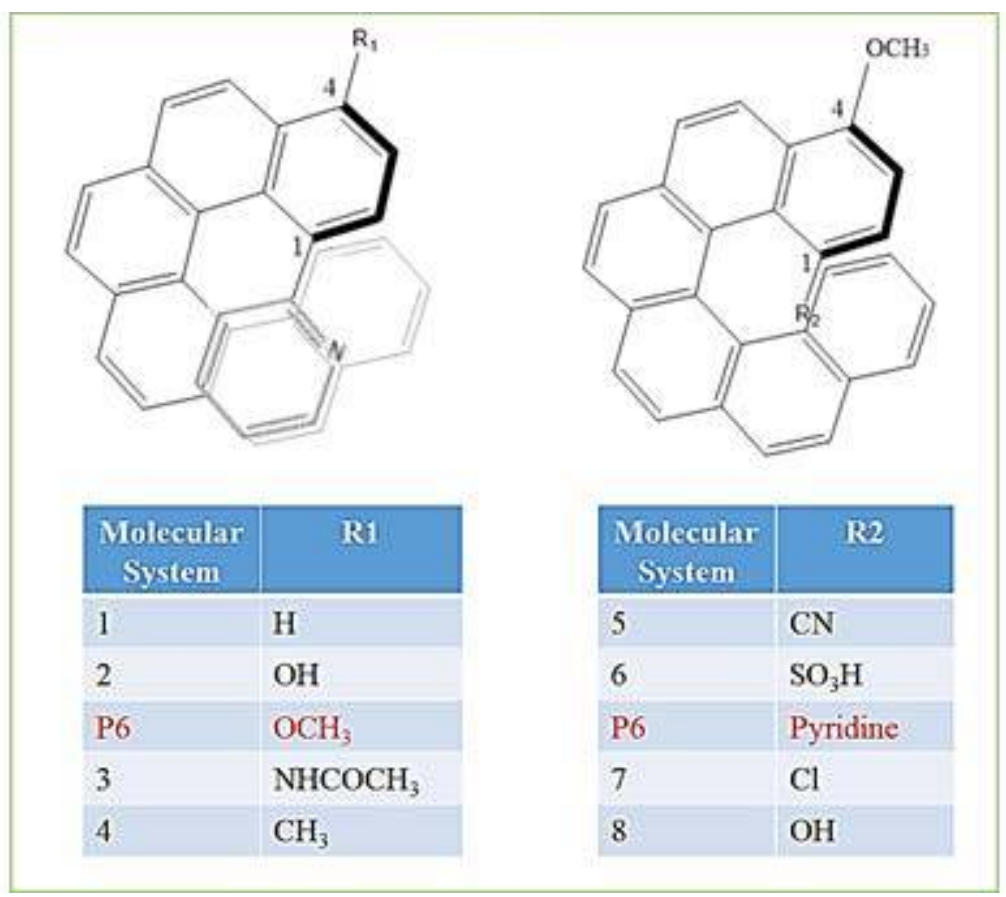

Figure 1. Chemical structures of $P-(+)-1-(2-p y r i d y l)-4-m e t h o x y[6]$ helicene (P6) and eight donor-acceptor $\mathbf{P 6}$ derivatives.

Then, we calculated the oscillator strengths $\left(f_{0 f}\right)$ and velocity rotatory strengths $\left(R_{0 f}^{E C D}\right)$ for the first 100 electronic excited states for $\mathbf{P 6}$ and all the donor-acceptor helicene derivatives 
employing Time-Dependent DFT (TD-DFT) ${ }^{39}$ at the CAM-B3LYP ${ }^{40} / 6-311++G(d, p){ }^{41-42}$ level of theory. CAM-B3LYP was selected as XCF because it has been proven to be more reliable than B3LYP in the prediction of excited states of molecules with ICT. Solvent effects were included in the calculations by using PCM ${ }^{44}$ in Gaussian $09^{43}$. The convoluted theoretical OPA and ECD spectra were obtained using Equations (1) and (2) with a Lorentzian shape and linewidth $(\Gamma)$ of $0.28 \mathrm{eV}(\mathrm{FWHM})$. OPA spectra are reported in molar absorptivity $(\varepsilon)$,

$$
\varepsilon^{O P A}(\omega) \approx 1.05495 \times 10^{3} \times \omega \sum_{f} g\left(\omega, \omega_{0 f}, \Gamma\right) \frac{f_{0 f}}{\omega_{0 f}}
$$

where $\omega$ is the circular frequency of the incident light and $g\left(\omega, \omega_{0 f}, \Gamma\right)$ is the line broadening function centered at $\omega=\omega_{0 f}$.

ECD spectra were calculated from $R_{0 f}^{E C D}$, and they are reported in molar absorptivity difference $(\Delta \varepsilon)$

$$
\Delta \varepsilon^{E C D}(\omega) \approx 2.73719 \times 10^{1} \times \omega \sum_{f} g\left(\omega, \omega_{0 f}, \Gamma\right) R_{0 f}^{E C D}
$$

The units of OPA and ECD are $\mathrm{mol}^{-1} \mathrm{~cm}^{-1} \mathrm{l}$, if the elements in equation (1) and (2) are in atomic units.

Finally, TPA probabilities $\left(\bar{\delta}_{0 f}^{T P A}\left(\omega_{0 f}\right)\right)$ and TPCD rotatory strength $\left(R_{0 f}^{T P C D}\left(\omega_{0 f}\right)\right)$ for $\mathbf{P 6}$ and all the eight theoretical donor-acceptor $\mathbf{P 6}$ derivatives were computed using TD-DFT ${ }^{39}$ in DALTON 2013. ${ }^{45}$ CAM-B3LYP ${ }^{40}$ hybrid functional was employed in combination with 6$311++G(d, p)$ basis set ${ }^{41-42}$ for the calculation of the first 60 electronic excited states for all the molecules. The number of excited states was selected based on the experimental spectral range (200 to $450 \mathrm{~nm}$ ) covered by the measurements. No solvent effects were taken into account in the nonlinear calculations due to the high computational cost. The convoluted theoretical TPA and TPCD spectra were obtained by a normalized Lorentzian shape with a linewidth $(\Gamma)$ of $0.2 \mathrm{eV}$ 
(FWHM).The $R_{0 f}^{T P C D}\left(\omega_{0 f}\right)$ were calculated from the electronic transitions employed in equations (3) and (4), where TPA spectra were simulated with,

$$
\delta^{T P A}(\omega) \approx 8.35150 \times 10^{-4} \times \omega^{2} \sum_{f} g\left(2 \omega, \omega_{0 f}, \Gamma\right) \bar{\delta}_{0 f}^{T P A}\left(\omega_{0 f}\right),
$$

here $g\left(2 \omega, \omega_{0 f}, \Gamma\right)$ is the line broadening function and $\bar{\delta}_{0 f}^{T P A}$ is the orientationally averaged twophoton probability for the degenerate case.

TPCD spectra were computed from,

$$
\Delta \delta^{T P C D}(\omega) \approx 4.87555 \times 10^{-5} \times \omega^{2} \sum_{f} g\left(2 \omega, \omega_{0 f}, \Gamma\right) R_{0 f}^{T P C D}\left(\omega_{0 f}\right),
$$

TPA and TPCD spectra computed from (3) and (4) are reported in Göppert-Mayer (GM), which is equivalent to $10^{-50} \mathrm{~cm}^{4} \mathrm{~s} \mathrm{~mol}^{-1}$ photon ${ }^{-1}$ when the elements of the equations are in atomic units.

In order to justify the use of the CAM-B3LYP hybrid functional for $\mathbf{P 6}$ we calculated the molecular orbitals involved in the most important electronic excitation on the red side of the theoretical ECD (\#3) spectrum. The obvious ICT observed in Figure 2, makes the selection of CAM-B3LYP reliable for our analysis. Similar evidences have already been reported by Rizzo and co-workers in various molecular systems. ${ }^{33,37,46-48}$ 


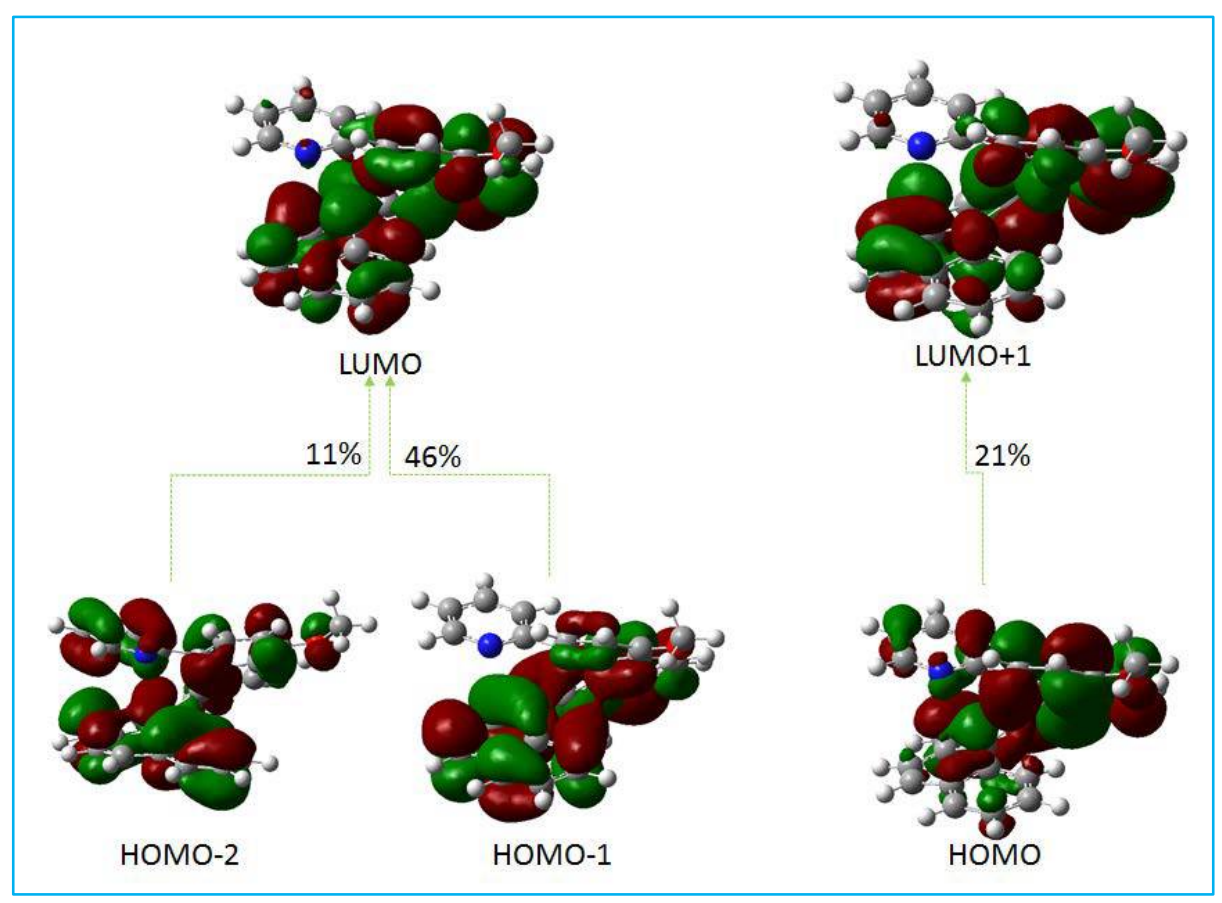

Figure 2. Molecular orbitals (MOs) involved in the 3rd electronic excited state of P6. The MOs were obtained from CAM-B3LYP/6-311++G(d,p) TD-DFT calculations in THF using PCM in Gaussian 09. The percent contribution of each single excitation ([HOMO-x] $\rightarrow$ [LUMO $+\mathrm{y}]$ to the excited state is indicated next to each arrow.

\section{RESULTS AND DISCUSSION}

In Figure 3, we show the experimental ECD and TPCD spectra for both enantiomers of P6, $M-(-)$ and $P-(+)-P 6$ in THF. From this Figure we can corroborate that TPCD is a sensitive technique for unequivocal enantiomeric identification. This is so, because one could say that the spectrum of one enantiomer is almost a specular image of the other, as expected. For this reason, the more extensive elucidation of the ECD and TPCD spectra of P6 will mainly focus on P-(+)P6, since similar arguments apply to $M-(-)-\mathbf{P 6}$. 


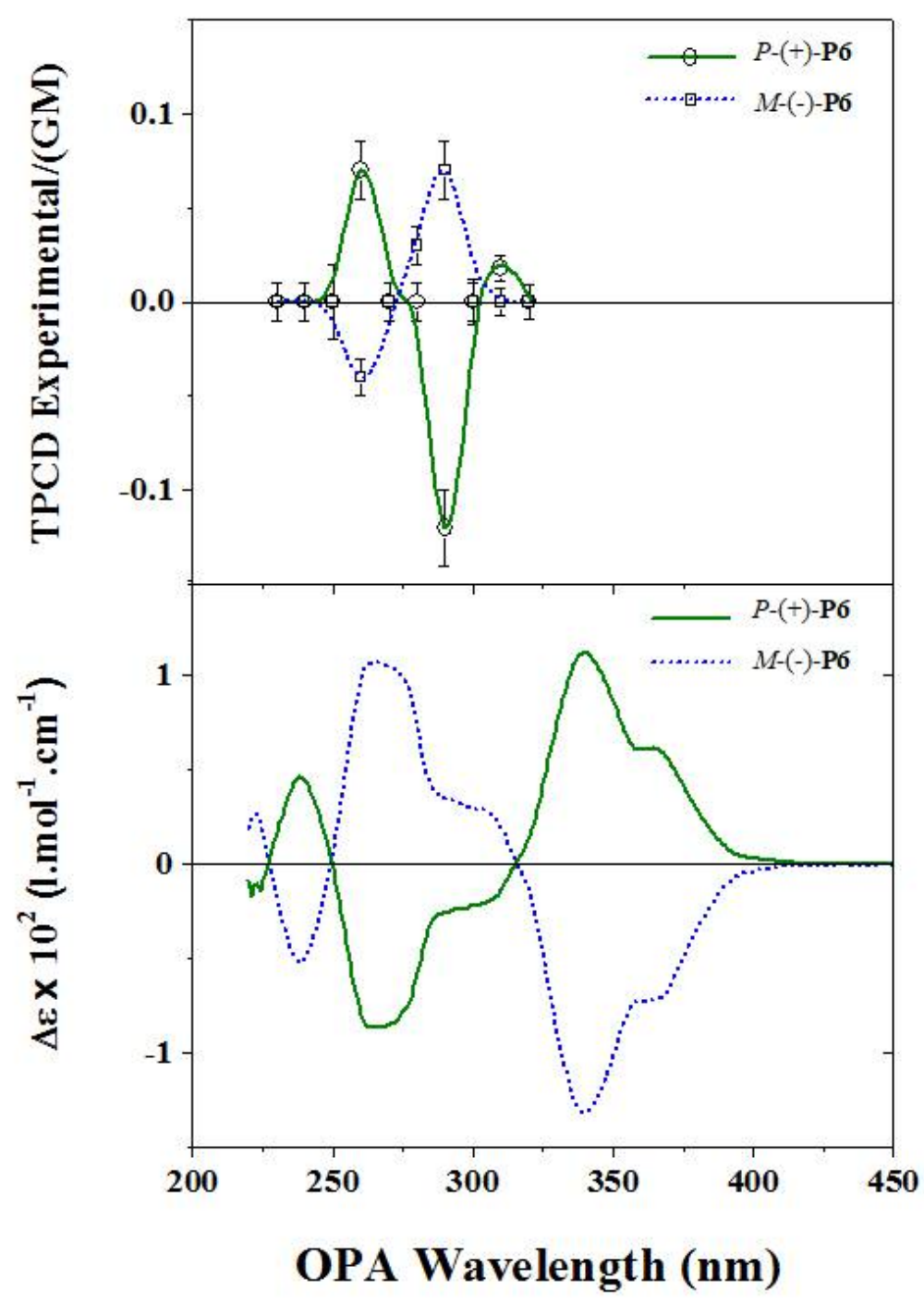

Figure 3. Experimental a) TPCD and b) ECD spectra for $P-(+)-\mathbf{P 6}$ and $M-(-)-\mathbf{P 6}$ in THF and dichloromethane, respectively.

Then, the experimental OPA and ECD spectra (Figure 4.a and b) and the experimental TPA and TPCD (see Figure 4.c and d) spectra of P6 in THF solution are presented in Figure 4. This figure also displays the corresponding convoluted theoretical linear (OPA and ECD) and nonlinear (TPA and TPCD) spectra - linear and nonlinear excited states were computed using TD-DFT. For the linear calculations (100 electronic excited states), solvent effects were considered using PCM. 
For the nonlinear theoretical spectra, the lowest 60 excited states were obtained without taking solvents effects into account due to high computational cost. In order to obtain a better overlapping between theoretical and experimental bands, the theoretical linear and nonlinear spectra were spectrally shifted by the amount reported in the caption of Figure 4. This is a common practice for theoretical-experimental works. ${ }^{24,33-34,36-37,46,49}$
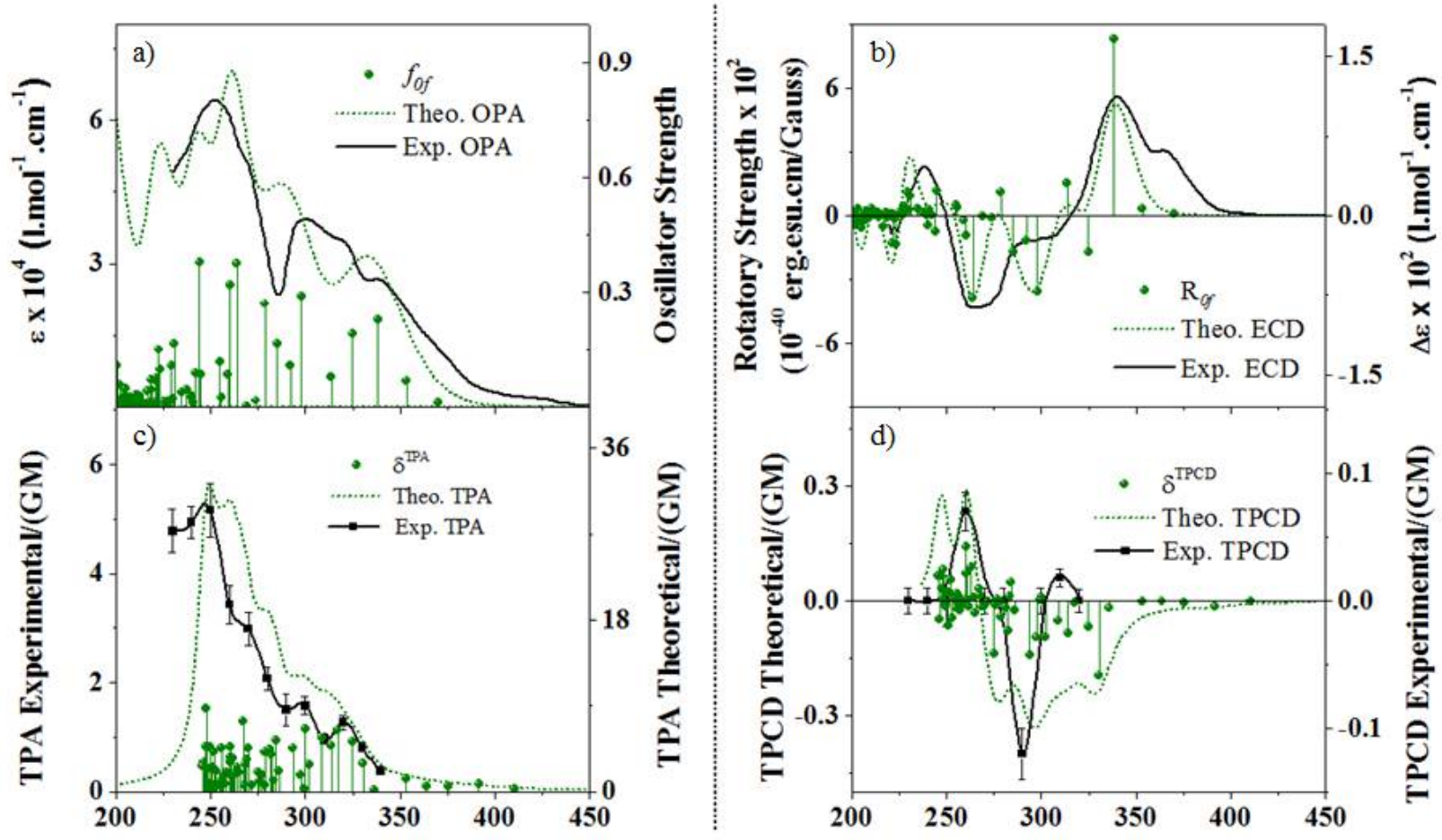

\section{OPA Wavelength (nm)}

Figure 4. Experimental (black solid and scattered line) and theoretical (green dotted line) of: a) UV-Vis, b) ECD, c) TPA, and d) TPCD spectra of $P-(+)-P 6$. Colored symbols display the oscillator strength in the case of UV-Vis and ECD and TPA probabilities and rotatory strength in the case of TPA and TPCD, respectively. The OPA and ECD were calculated for the 100 lowest electronic excited states at the CAM-B3LYP/6-311++G(d,p) level of theory using Gaussian 09 in THF employing PCM. The theoretical linear spectra are only shown within the measurable spectral range (200-450 nm) with $+10 \mathrm{~nm}$ spectral shift. $\Gamma=0.28 \mathrm{eV}$ (FWHM) was used for OPA and ECD. The TPA and TPCD spectra were computed for the first 60 excited states at the CAMB3LYP/6-311++G(d,p) level of theory in vacuo using Dalton 2013. The theoretical shift for the 
non-linear spectra was $+50 \mathrm{~nm}$ and the $\Gamma=0.2 \mathrm{eV}$ (FWHM).

The first interesting observation to highlight from Figure 4 is the remarkable theoreticalexperimental overlapping in all four spectra. The theoretical spectra extraordinarily reproduced the shape, position of the bands, and the fano-type shape profile of the experimental spectra. As mentioned before, the great performance of the chosen XCF is attributed to the presence of ICT in P6. The second important observation is the differences in TPA cross-sections between theoretical and experimental spectra, where the former is larger than the latter. This differences have been previously observed in other molecules ${ }^{46,49}$ and are very hard to explain considering the fact that the measurements were performed in the femtosecond regime where excited state absorption is almost negligible. ${ }^{50-51}$ Next, it is worth noting that the sign and relative intensities of the two main bands (290 and $260 \mathrm{~nm}$ ) in TPCD were notably reproduced.

In order to gain more insight about the effects of a structural motif on the linear and nonlinear chiroptical properties of conjugated organic molecules with helical chirality, we embarked on a theoretical investigation of several molecular systems with different terminal donor-acceptor motifs on the helicene core of P6-like structures (see Figure 1). We performed calculations of OPA, ECD, TPA, and TPCD on four different moieties on position 1 and four different substituents in position 4 (see Figure 1). The substituents were selected based on their ability to affect the electron density of the helicene core. In order to perform a systematic selection of the corresponding substituents, we used the Hammet parameter $(\sigma)$, which provides a qualitative (negative $\sigma$ for electron releasing and positive for electron withdrawing substituents) and quantifiable scale for the electron withdrawing and releasing strength of the groups (see Tables 1 and 2). ${ }^{52-53}$ 
Table 1. Hammet $\sigma$-constant for substituents of position 4.

\begin{tabular}{|c|c|}
\hline Substituent Position 4 & Hammet $\boldsymbol{\sigma}$-constant \\
\hline H & 0 \\
\hline OH & -0.37 \\
\hline P6 & -0.27 \\
\hline NHCOCH$_{3}$ & -0.15 \\
\hline $\mathbf{C H}_{3}$ & 0.23 \\
\hline
\end{tabular}

Table 2. Hammet $\sigma$-constant for substituents of position 1.

\begin{tabular}{|c|c|}
\hline Substituent Position 1 & Hammet $\boldsymbol{\sigma}$-constant \\
\hline $\mathbf{C N}$ & 0.66 \\
\hline $\mathrm{SO}_{3} \mathbf{H}$ & 0.30 \\
\hline $\mathbf{C l}$ & 0.23 \\
\hline P6 & -0.05 \\
\hline $\mathbf{O H}$ & -0.37 \\
\hline
\end{tabular}

In Figure 5, we present the comparative plot of the OPA, ECD, TPA and TPCD theoretical spectra for all four different substituents for position 4, as well as the theoretical spectra for P6.

First, we decided to vary the substituent in position 4, keeping the substituent in position 1 as in P6 (see the combinations in Figure 1). The OPA and ECD signals are not strongly affected by the nature of the substituents in this position. In this figure, one can only observe an almost negligible increase in the amplitude and a red shift on the red side of the fano-type band of the ECD signal. 
Figure 5. OPA, ECD, TPA, and TPCD theoretical spectra of all different substituents of position 4 including P6. OPA and ECD were obtained from the Lorentzian convolution $(\Gamma=0.2 \mathrm{eV}$ FWHM) of the first 60 excited states of their optimized structures calculated at the CAMB3LYP/6-311++G(d,p) level of theory in THF using PCM employing Gaussian 09. TPA and TPCD spectra of all optimized structures were obtained from the Lorentzian convolution $(\Gamma=0.2$ $\mathrm{eV}(\mathrm{FWHM})$ ) of the first 60 excited states. The nonlinear calculations were performed at CAMB3LYP/6-311++G(d,p) level of theory in vacuo using Dalton 2013.

In TPA, two main bands are identified, the first at approximately $260 \mathrm{~nm}$ and the second at $200 \mathrm{~nm}$. The intensity of the first band is similar in all five derivatives. However, the second band changes its intensity from $20 \mathrm{GM}$ in $\mathrm{H}$ to $34 \mathrm{GM}$ in $\mathrm{NHCOCH}_{3}$. In the TPCD spectra, one can also notice that the first band is unaffected by the substitution in position 4. However, the apparent change in intensity observed in the second band of the $-\mathrm{NHCOCH}_{3}$ derivative is attributed to the fusion of the double-peak band present in the other four molecules to produce an intense single- 
peak band.

Next, we varied the substituent in position 1, keeping the moiety in position 4 as in $\mathbf{P 6}$ (see the combinations in Figure 1). In Figure 6, we present the OPA spectra of the four derivatives of the second series. Interesting to highlight is the small red shift (30 nm) experienced by the band centered at approximately $320 \mathrm{~nm}$ in $-\mathrm{CN},-\mathrm{SO}_{3} \mathrm{H}$, and $\mathbf{P 6}$. Likewise in ECD, we see a similar shift in the same three derivatives. This interesting result reveals the extension of the conjugation length introduced by the pyridine moiety on the outside of the helicene core in P6, an effect not present in the other four derivatives.

Moving on to the TPA spectra, another interesting point to highlight, which is only observed in the two strongest electron withdrawing groups, is the presence of a strong band at approximately 180 nm, which TPA cross section varies from 28 GM for P6 to 48 GM for the $-\mathrm{SO}_{3} \mathrm{H}$ substituted. This result is supported by previous theoretical results published by Yan and co-workers (2012), where they demonstrated that conjugated molecules with a push-pull motif present an enhanced TPA cross section as a result of the intramolecular charge transfer, which increases the electric dipole transition moments between the ground and excited states. ${ }^{54}$ To corroborate this finding, we calculated the resultant electric dipole transition moment for the $3^{\text {rd }}$ electronic excited state (see Table 3) - same electronic excited state selected previously for corroborating the charge transfer character of P6. As expected, one can clearly see that, at least for this electronic excited state, the resultant electric dipole transition moment is larger for $\mathrm{CN}$ and $\mathrm{SO}_{3} \mathrm{H}$ than for $\mathbf{P 6}$. 
Table 3. Comparison of the resultant of the electric dipole transition moment of the two groups with the highest electron withdrawing character $\left(\mathrm{CN}\right.$ and $\left.\mathrm{SO}_{3} \mathrm{H}\right)$ and $\mathbf{P 6}$.

\begin{tabular}{|l|c|}
\hline State 3 & $\begin{array}{c}\text { Resultant of the Electric } \\
\text { dipole transition moment } \\
\text { (AU) }\end{array}$ \\
\hline $\mathrm{CN}$ & 2.14327 \\
\hline $\mathrm{SO}_{3} \mathrm{H}$ & 2.00440 \\
\hline $\mathbf{P 6}$ & 1.57353 \\
\hline
\end{tabular}
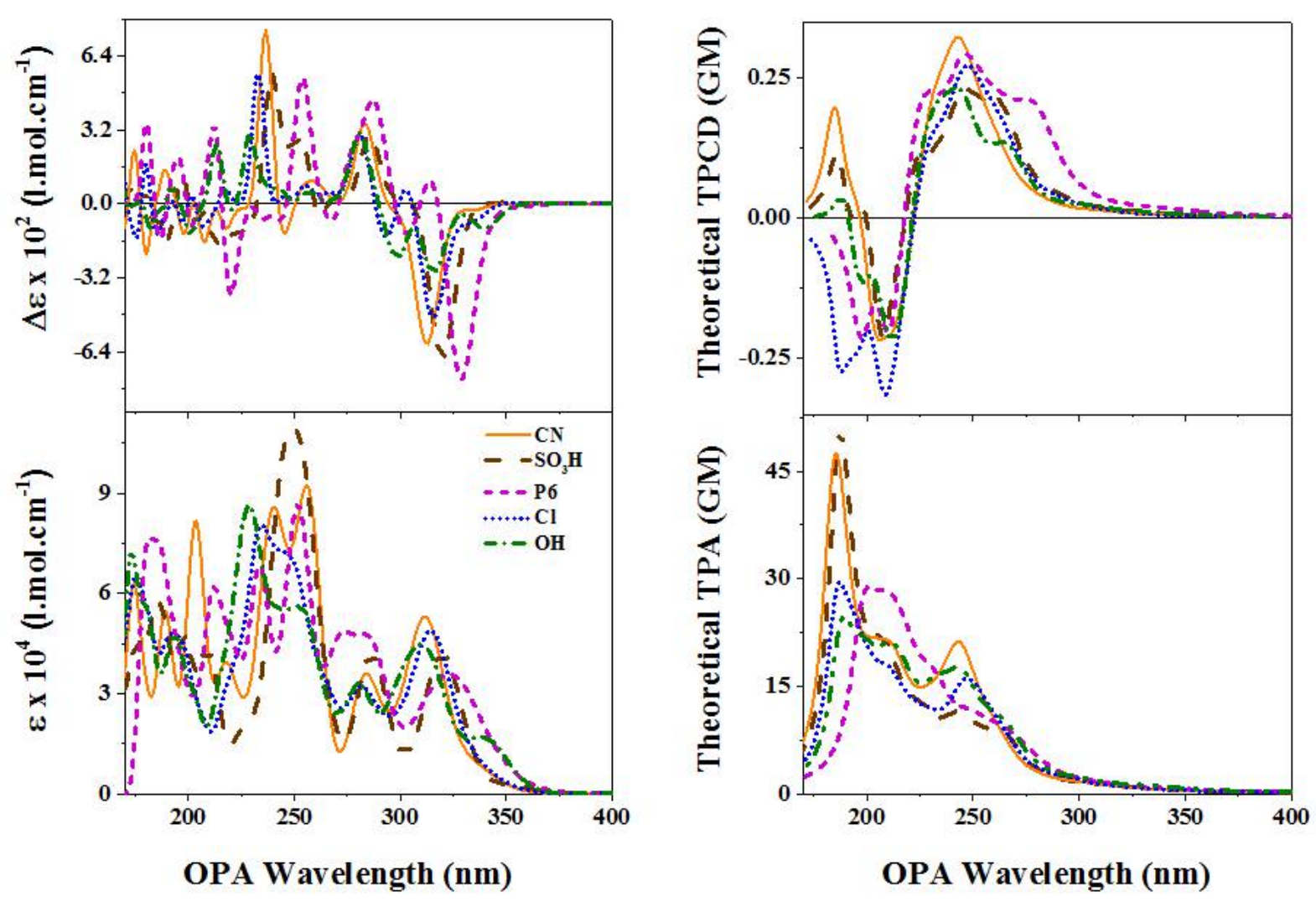

Figure 6. OPA, ECD, TPA and TPCD theoretical spectra of all five different substituents. OPA and ECD spectra were obtained from the Lorentzian convolution $(\Gamma=0.2 \mathrm{eV}$ FWHM) of the first 100 electronic excited states of the optimized structures of all different five substituents at the CAM-B3LYP/6-311++G(d,p) level of theory in THF using PCM and employing Gaussian 09. TPA and TPCD spectra of the optimized structures were calculated from the Lorentzian convolution $(\Gamma=0.2 \mathrm{eV}$ FWHM) for the first 60 electronic excited states. TPA and TPCD 
calculations were performed at the CAM-B3LYP/6-311++G(d,p) level of theory in vacuo using Dalton 2013.

The molecular orbitals for the most important single excitations contributing to the $3^{\text {rd }}$ excited state of $\mathrm{SO}_{3} \mathrm{H}$ presented in Figure 7, evidently expose the greater ICT character of $-\mathrm{SO}_{3} \mathrm{H}$ when compared to $\mathbf{P 6}$ (see Figure 3). On the one hand, in the HOMO and HOMO-1 energy levels, one can see that the electrons are mainly delocalized in the aromatic ring of the molecular system. In the LUMO and LUMO+1 energy levels, the electron density goes more towards the $-\mathrm{SO}_{3} \mathrm{H}$ group due to its higher electron withdrawing character. Consequently, the ICT effect is more evident in the helicene with the $-\mathrm{SO}_{3} \mathrm{H}$ substituent than in $\mathbf{P 6}$.

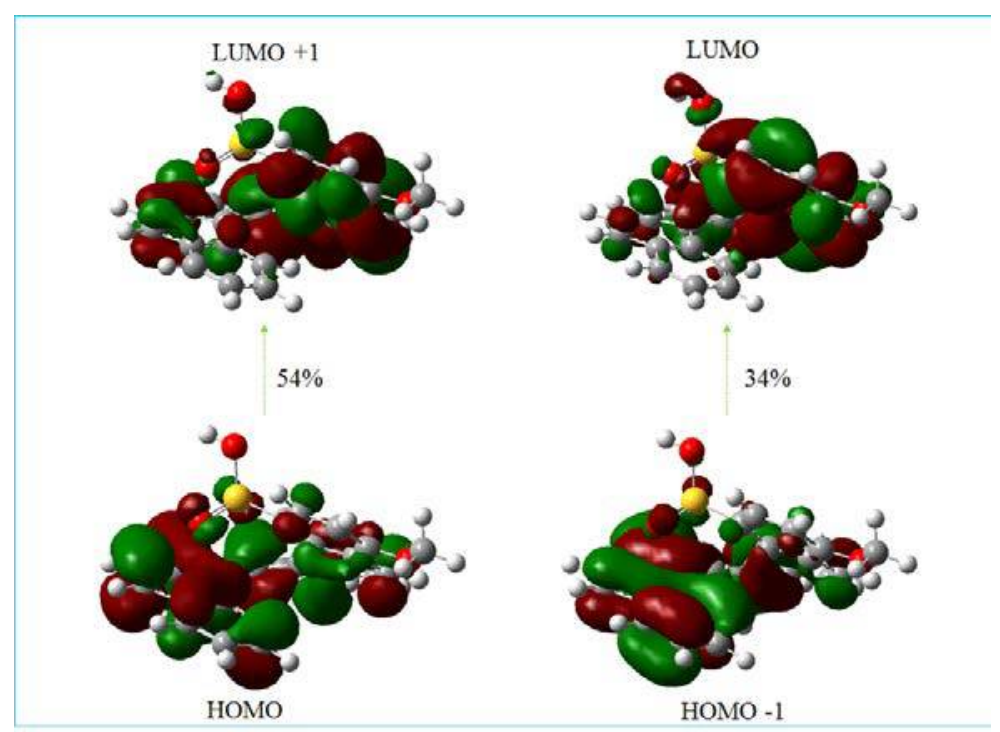

Figure 7. Molecular orbitals (MOs) involved in the 3rd electronic excited state of $\mathrm{SO}_{3} \mathrm{H}$. The MOs were obtained from CAM-B3LYP/6-311++G(d,p) TD-DFT calculations in THF using PCM in Gaussian 09. The percent contribution of each single excitation ([HOMO-x] $\rightarrow[\mathrm{LUMO}+\mathrm{y}])$ to the excited state is indicated next to each arrow. 
Finally, we analyzed the TPCD spectra of all five substituents in position 1 (Figure 6). Once again, the positive band that appears towards the red side of the spectra seems to be unaffected by the donor-acceptor combination of the substituents. However, the band located at approximately $200 \mathrm{~nm}$ changed in shape and sign. In the case of $\mathbf{P 6}$ and -Cl, one can notice a negative doublepeak band in this region. For $-\mathrm{CN}$ and $-\mathrm{SO}_{3} \mathrm{H}$, this band emerges as a negative single-peak band at $210 \mathrm{~nm}$ that turns into a positive band at $180 \mathrm{~nm}$. Knowing that TPCD signal directly depends on the different contributions from the electric quadrupole transition moment (accounted for on the molecular parameter $\mathrm{B}_{2}$ ) and the magnetic dipole transition moment (accounted for on the molecular parameters $\mathrm{B}_{1}$ and $\mathrm{B}_{3}$ ), a comparison of the sum of the absolute values of molecular parameters $B_{1}+B_{3}$ and $B_{2}$ for all five substituents in position 1 and 4 is presented in Figure 8 .
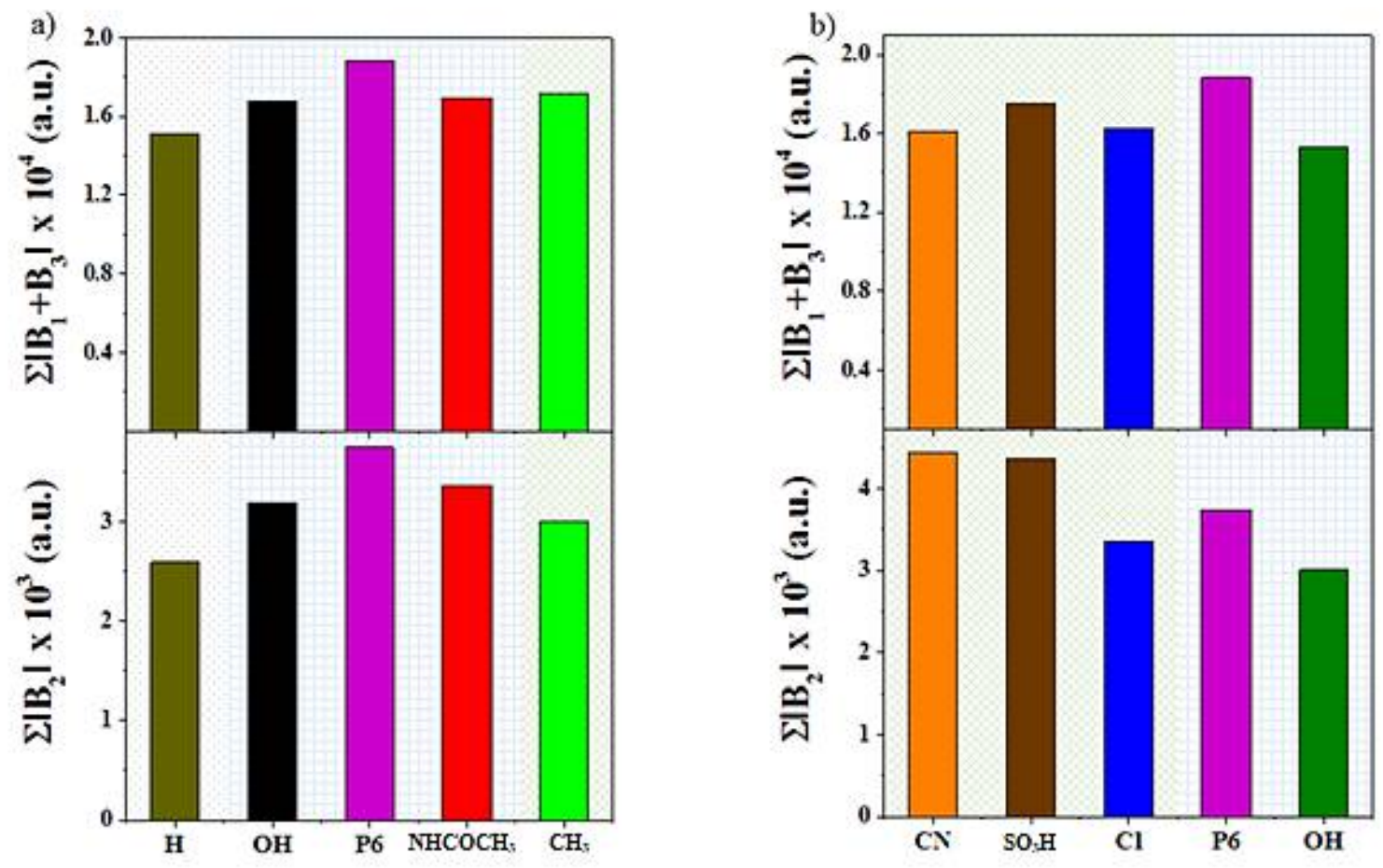

Figure 8. Comparative bar graph of a) $\sum\left|B_{1}+B_{3}\right|$ and b) $\sum\left|B_{2}\right|$ for all substituents of a) position 4 and b) position 1 . 
In this Figure, one can identify three main groups (identify with different backgrounds patterns and colors): the blue squared pattern indicates that these substituents act as electron releasing groups based on their negative Hammet constant, the green diagonal cross pattern designates the electron withdrawing groups with positive Hammet constants, and the grey dotted area corresponds to $-\mathrm{H}$, which was used as a reference (see tables 1 and 2). ${ }^{52}$

The analysis of the different highlighted regions in the Figure shows a clear trend on the contribution of the magnetic dipole transition moment $\left(\Sigma\left|\mathrm{B}_{1}+\mathrm{B}_{3}\right|\right)$ to the TPCD spectra with respect to their donor-acceptor character. It can be observed that $\Sigma\left|\mathrm{B}_{1}+\mathrm{B}_{3}\right|$ is always greater for $\mathbf{P 6}$ than the P6-like molecules with different substituents. However, the contribution of the electric quadrupole transition moment $\left(\Sigma\left|\mathrm{B}_{2}\right|\right)$ to the TPCD spectra is larger for $\mathbf{P 6}$ on the electron releasing moieties and larger for $-\mathrm{CN}$ on the electron withdrawing series. In order to explain these trends, we calculated the HOMO and LUMO energies for each P6-like derivative, P6 included, employing DFT. The calculated energies, as well as the energy gaps of these molecules are presented in Figure 9.

From Figure 9.a, which compares the effect of the strength of donor groups in position 4, one can deduce that as the electron releasing character increases, so does the LUMO energy of the helicene derivatives. This is corroborated by the change in tendency observed in a weak electron withdrawing substituent such as $-\mathrm{CH}_{3}$ ) (the LUMO energy increases again, Figure 9.a). Now, in Figure 9.b, which assesses the effect of the strength of attractor groups in position 1, one can observe an overall decrease of the LUMO energy as the electron withdrawing character increases. After completing the examination of the effect of contributions of $\sum\left|\mathrm{B}_{1}+\mathrm{B}_{3}\right|$ and $\sum\left|\mathrm{B}_{2}\right|$ to the TPCD spectra of both series of P6-like derivatives (Figure 8), and the effect of energy gap (HOMO-LUMO) in the same two series, we proceeded to evaluate the existing correlations 
between the two. Through this analysis, an inverse dependency between the magnetic dipole transition moment contribution to the TPCD and the energy gap was noticed, i.e. the lower the energy gap the higher $\sum\left|\mathrm{B}_{1}+\mathrm{B}_{3}\right|$. This can be explained based on previous works reporting that a decrease in energy gap causes and increase in the angular momentum.$^{55}$ Therefore, because the angular momentum is directly correlated with the magnetic moment, an increase in the angular momentum results in a higher magnetic dipole transition moment. ${ }^{56}$
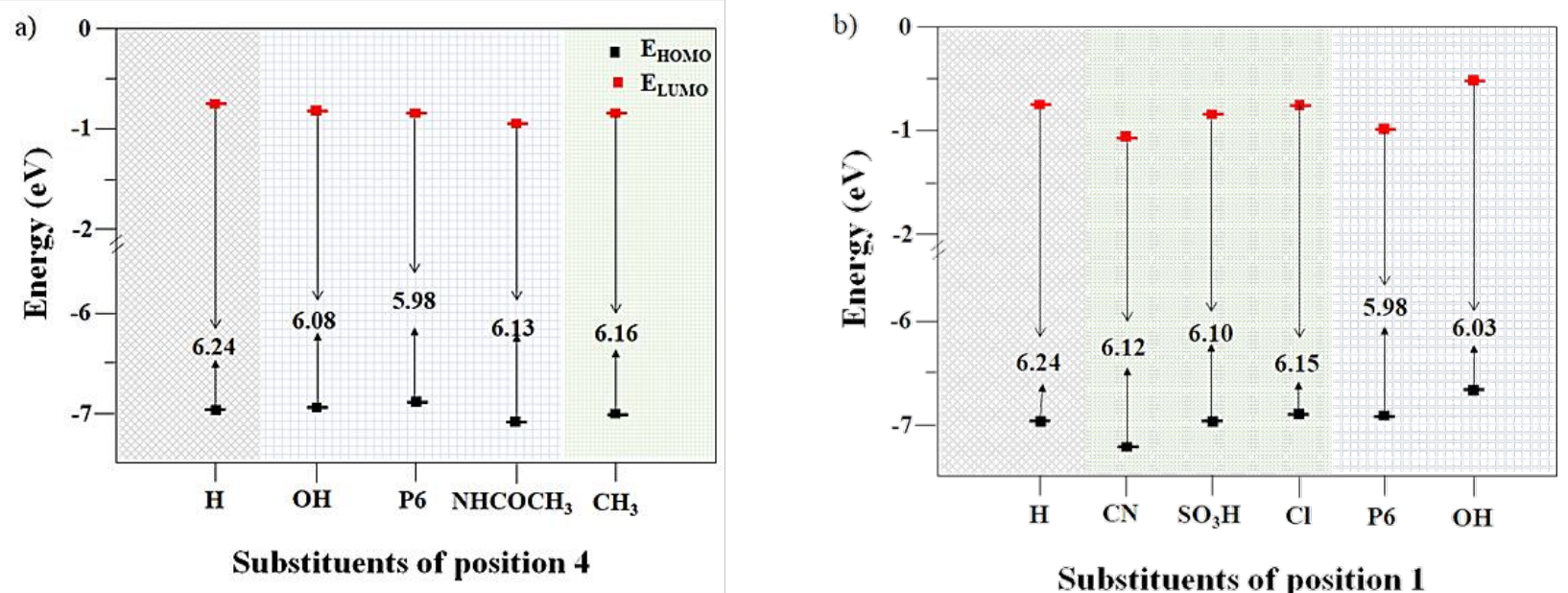

Substituents of position 1

Figure 9. Calculated HOMO energies, LUMO energies, and energy gaps of all the donoracceptor combinations substituents for a) position 4 and b) position 1 .

In order to corroborate the established correlation between $\sum\left|\mathrm{B}_{1}+\mathrm{B}_{3}\right|$ and $\sum\left|\mathrm{B}_{2}\right|$ and the donoracceptor combination in $\mathbf{P 6}$ derivatives, we calculated the frontier molecular orbitals (FMOs) of all nine molecules (see Figure 10). The FMOs were obtained using DFT. In Figure 10.a, one can observe, in most of the derivatives, that the electron density over the substituents on one end of the molecule is higher in the HOMO than in the LUMO. This reveals the strong electron withdrawing character of the helical core in P6-like derivatives with different electron donating moieties. On the contrary, the FMOs presented in Figure 10.b show a strong ICT between the two moieties with push-pull arrangement on one end on the derivatives rather than through the helicene 
core. In summary, the presence of strong withdrawing substituents such as $-\mathrm{CN}$ and $-\mathrm{SO}_{3} \mathrm{H}$ in position 1 tend to originate a larger contribution to TPCD through the electric quadrupole transition moment, while the pure existence of an aromatic ring like pyridine in $\mathbf{P 6}$ that can extend the length of the $\pi$-electron delocalization beyond the helical core creates a stronger contribution to TPCD through the magnetic dipole transition moment.
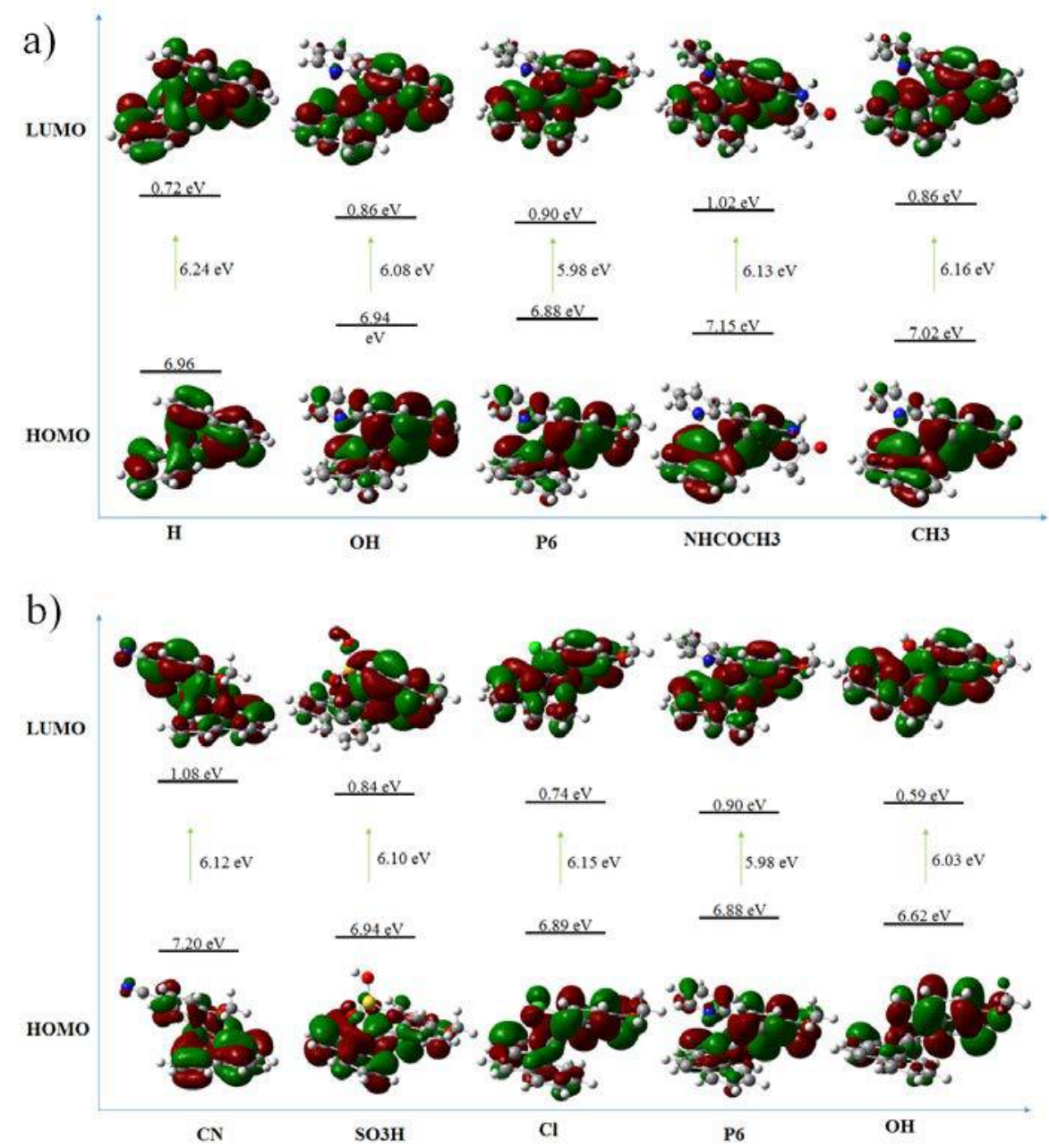

Figure 10. The Frontier Molecular Orbitals (FMOs) of all substituents of a) position 4 and b) position 1. The molecular orbitals were obtained using DFT at the CAM-B3LYP/6-311++G(d,p) level of theory in THF using PCM and employing Gaussian 09. 


\section{CONCLUSIONS}

It was observed that one-photon signals are not strongly affected by the nature of the substituents. However, it was demonstrated that TPA and more specifically TPCD are more sensitivy to structural changes.Furthermore, the analysis of the effect of localized ICT on one end of helicene derivatives on the contribution transition moments of TPA and TPCD revealed that: a) the lengthening of the $\pi$-electron delocalization, within the helical core of $\mathbf{P 6}$, predominantly increases the contribution of the magnetic dipole transition moment to the TPCD signal, and b) the electric quadrupole transition moment contribution to the TPCD signal is enhanced by the localized ICT produced by the donor-acceptor combination on one end of the molecule. These two effects were certified by the analysis of FMOs in all the nine derivatives.

\section{ACKNOWLEDGEMENTS}

Jeanne Crassous thanks the Ministère de l'Education Nationale, de la Recherche et de la Technologie and the Centre National de la Recherche Scientifique (CNRS). This work has been partially supported by the National Science Foundation through Grant Number NSF/ARRA0840431 and NSF/DBI-1422826. The extended computing time provided by STOKES ARCC/UCF is gratefully acknowledged. 


\section{REFERENCES}

1. Shen, Y.; Chen, C.-F., Helicenes: Synthesis and Applications. Chemical reviews 2011, 112, 1463-1535.

2. Gingras, M., One Hundred Years of Helicene Chemistry. Part 3: Applications and Properties of Carbohelicenes. Chemical Societv Reviews 2013, 42, 1051-1095.

3. $\quad$ Chen, C.-F.; Shen, Y., Helicene Chemistry: From Synthesis to Applications. Springer: 2016.

4. Aillard, P.; Voituriez, A.; Marinetti, A., Helicene-like Chiral Auxiliaries in Asymmetric Catalysis. Dalton Transactions 2014, 43, 15263-15278.

5. Narcis, M. J.; Takenaka, N., Helical-Chiral Small M olecules in Asymmetric Catalysis. European Journal of Oraanic Chemistrv 2014, 2014, 21-34.

6. Isla, H.; Crassous, J., Helicene-based chiroptical switches. Comptes Rendus Chimie 2016, 19, 39-49.

7. Reetz, M. T.; Sostmann, S., 2,15-Dihydroxy-hexahelicene (HELIXOL): Synthesis and Use as an Enantioselective Fluorescent Sensor. Tetrahedron 2001, 57, 2515-2520.

8. Field, J. E.; Muller, G.; Riehl, J. P.; Venkataraman, D., Circularly Polarized Luminescence from Bridged Triarylamine Helicenes. Journal of the American Chemical Society 2003, 125, 11808-11809.

9. Hassey, R.; Swain, E. J.; Hammer, N. I.; Venkataraman, D.; Barnes, M. D., Probing the Chiroptical Response of a Single Molecule. Science 2006, 314, 1437-1439.

10. Verbiest, T.; Elshocht, S. V.; Kauranen, M.; Hellemans, L.; Snauwaert, J.; Nuckolls, C.; Katz, T. J.; Persoons, A., Strong Enhancement of Nonlinear Optical Properties Through Supramolecular Chirality. Science 1998, 282, 913-915. 
11. Verbiest, T.; Sioncke, S.; Persoons, A.; Vyklicky, L.; Katz, T. J., Electric-Field-Modulated Circular-Difference Effects in Second-Harmonic Generation from a Chiral Liquid Crystal. Angew Chem Int Ed Enal 2002, 41, 3882-4.

12. Nakanishi, K.; Berova, N.; Woody, R. W., Circular Dichroism: Principles and Applications. 2nd ed.; VCH: New York, 2000.

13. Condon, E. U.; Altar, W.; Eyring, H., Theories of Optical Rotatory Power. Reviews of Modern Phvsics 1937, 9, 432-457.

14. Caldwell, D. J.; Eyring, H., The Theory of Optical Activity. Wiley-Interscience: New York, 1971.

15. Tinoco, I., Jr.; Mickols, W.; Maestre, M. F.; Bustamante, C., Absorption, Scattering, and Imaging of Biomolecular Structures with Polarized Light. Annu Rev Biophys Biophys Chem 1987, 16, 319-49.

16. Nafie, L. A., Vibrational Optical Activity: Principles and Applications. John Wiley \& Sons: West Sussex, 2011.

17. Barron, L. D., Molecular Light Scattering and Optical Activity. Cambridge University Press: Cambridge, 2004.

18. Mason, W. R. A., Practical Guide to Magnetic Circular Dichroism Spectroscopy. John Wiley \& Sons: New Jersey, 2007.

19. Miles, A. J.; Wallace, B. A., Synchrotron Radiation Circular Dichroism Spectroscopy of Proteins and Applications in Structural and Functional Genomics. Chemical Society reviews 2006, 35, 39-51.

20. Cameron, R.; Tabisz, G. C., Observation of Two-Photon Optical Rotation by Molecules. Molecular Phvsics 1997, 90, 159-164. 
21. Ji, N.; Ostroverkhov, V.; Belkin, M.; Shiu, Y. J.; Shen, Y. R., Toward Chiral SumFrequency Spectroscopy. Journal of the American Chemical Societv 2006, 128, 8845-8848.

22. Fischer, P.; Hache, F., Nonlinear Optical Spectroscopy of Chiral Molecules. Chirality 2005, 17, 421-37.

23. Rizzo, A.; Agren, H., Ab Initio Study of the Circular Intensity Difference in Electric-FieldInduced Second Harmonic Generation of Chiral Natural Amino Acids. Physical Chemistry Chemical Physics 2013, 15, 1198-1207.

24. Toro, C.; De Boni, L.; Lin, N.; Santoro, F.; Rizzo, A.; Hernandez, F. E., Two-Photon Absorption Circular Dichroism: A New Twist in Nonlinear Spectroscopy. Chem. Eur. J. 2010, 16, $3504-9$.

25. Tinoco, I., Two-Photon Circular Dichroism. L. Chem. Phvs. 1975, 62, 1006-1009.

26. Power, E. A., Two-Photon Circular Dichroism. L.Chem. Phvs. 1975, 63, 1348-1350.

27. Hernández, F. E.; Rizzo, A., Two-Photon Polarization Dependent Spectroscopy in Chirality: a Novel Experimental-Theoretical Approach to Study Optically Active Systems. Molecules (Basel, Switzerland) 2011, 16, 3315-37.

28. Denk, W.; Strickler, J.; Webb, W., Two-Photon Laser Scanning Fluorescence Microscopy. Science 1990, 248, 73-76.

29. Cumpston, B. H.; Ananthavel, S. P.; Barlow, S.; Dyer, D. L.; Ehrlich, J. E.; Erskine, L. L.; Heikal, A. A.; Kuebler, S. M.; Lee, I.-Y. S.; McCord-Maughon, D.; et. al., Two-Photon Polymerization Initiators for Three-Dimensional Optical Data Storage and Microfabrication. Nature 1999, 398, 51-54. 
30. Vesga, Y.; Diaz, C.; Higgs, M.; Hernandez, F. E., Two-Photon Circular Dichroism of Molecular Structures Simulating L-tryptophan Residues in Proteins with Secondary Structures. Chem. Phvs._Lett. 2014, 601, 6-12.

31. Gunde, K. E.; Richardson, F. S., Fluorescence-Detected Two-Photon Circular Dichroism of $\mathrm{Gd}^{3+}$ in Trigonal $\mathrm{Na}_{3}\left[\mathrm{Gd}\left(\mathrm{C}_{4} \mathrm{H}_{4} \mathrm{O}_{5}\right)_{3}\right] \cdot 2 \mathrm{NaClO}_{4} \cdot 6 \mathrm{H}_{2} \mathrm{O}$. Chemical Phvsics 1995, 194, 195-206. 32. De Boni, L.; Toro, C.; Hernandez, F. E., Synchronized Double L-Scan Technique for the Simultaneous Measurement of Polarization-Dependent Two-Photon Absorption in Chiral Molecules. Opt. Lett. 2008, 33, 2958-2960.

33. Díaz, C.; Echevarria, L.; Rizzo, A.; Hernández, F. E., Two-Photon Circular Dichroism of an Axially Dissymmetric Diphosphine Ligand with Strong Intramolecular Charge Transfer. J. Phvs. Chem. A 2014, 118, 940-946.

34. Díaz, C.; Echevarria, L.; Hernández, F. E., Conformational Study of an Axially Chiral Salen Ligand in Solution using Two-Photon Circular Dichroism and the Fragment-Recombination Approach. J. Phys. Chem. A

2013, 117, 8416-8426.

35. Diaz, C.; Echevarria, L.; Hernández, F. E., Overcoming the Existent Computational Challenges in the Ab Initio Calculations of the Two-Photon Circular Dichroism Spectra of Large Molecules using a Fragment-Recombination Approach. Chem. Phys. Lett. 2013, 568-569, 176183.

36. Diaz, C.; Lin, N.; Toro, C.; Passier, R.; Rizzo, A.; Hernández, F. E., The Effect of the $\pi-$ Electron Delocalization Curvature on the Two-Photon Circular Dichroism of Molecules with Axial Chirality. L.Phvs. Chem. Lett. 2012, 3, 1808-1813. 
37. Lin, N.; Santoro, F.; Zhao, X.; Toro, C.; De Boni, L.; Hernández, F. E.; Rizzo, A., Computational Challenges in Simulating and Analyzing Experimental Linear and Nonlinear Circular Dichroism Spectra. R-(+)-1,1'-bis(2-naphthol) as a Prototype Case. journal of physical chemistry. B 2011, 115, 811-24.

38. Shen, C.; Anger, E.; Srebro, M.; Vanthuyne, N.; Deol, K. K.; Jefferson, T. D.; Muller, G.; Williams, J. G.; Toupet, L.; Roussel, C., Straightforward Access to Mono-and Bis-cycloplatinated Helicenes Displaying Circularly Polarized Phosphorescence by Using Crystallization Resolution Methods. Chemical science 2014, 5, 1915-1927.

39. Runge, E.; Gross, E. K. U., Density-Functional Theory for Time-Dependent Systems. Phvs. Rev. Lett. 1984, 52, 997-1000.

40. Yanai, T.; Tew, D. P.; Handy, N. C., A new Hybrid Exchange-Correlation Functional using the Coulomb-Attenuating Method (CAM-B3LYP). Chem. Phvs. Lett. 2004, 393, 51-57.

41. Krishnan, R.; Binkley, J. S.; Seeger, R.; Pople, J. A., Self-Consistent M olecular Orbital Methods. XX. A Basis Set for Correlated Wave Functions. J.Chem. Phvs. 1980, 72, 650-654.

42. Clark, T.; Chandrasekhar, J.; Spitznagel, G. W.; Schleyer, P. V. R., Efficient Diffuse Function-Augmented Basis Sets for Anion Calculations. III. The 3-21+G Basis Set for First-Row Elements, Li-F. J. Comput. Chem. 1983, 4, 294-301.

43. Frisch, M. J.; Trucks, G. W.; Schlegel, H. B.; Scuseria, G. E.; Robb, M. A.; Cheeseman, J. R.; Scalmani, G.; Barone, V.; Mennucci, B.; Petersson, G. A.; et.al., Gaussian 09, Revision A.1. Gaussian, Inc.: Wallingford CT, 2009.

44. Tomasi, J.; Mennucci, B.; Cammi, R., Quantum Mechanical Continuum Solvation Models. Chem. Rev. 2005, 105, 2999-3093. 
45. Aidas, K.; Angeli, C.; Bak, K. L.; Bakken, V.; Bast, R.; Boman, L.; Christiansen, O.; Cimiraglia, R.; Coriani, S.; Dahle, P.; et.al., The Dalton Quantum Chemistry Program System. Wilev Interdiscin. Rev. Comput. Mol.Scj. 2014, 4, 269-284.

46. Diaz, C.; Vesga, Y.; Echevarria, L.; Stará, I. G.; Starỳ, I.; Anger, E.; Shen, C.; Moussa, M. E. S.; Vanthuyne, N.; Crassous, J.; Rizzo, A.; Hernandez, F. E., Two-photon Absorption and Twophoton Circular Dichroism of Hexahelicene Derivatives: A Study of the Effect of the Nature of Intramolecular Charge Transfer. RSC Adv. 2015, 5, 17429-17437.

47. Lin, N.; Santoro, F.; Rizzo, A.; Luo, Y.; Zhao, X.; Barone, V., Theory for Vibrationally Resolved Two-Photon Circular Dichroism Spectra. Application to (R)-(+)-3Methylcyclopentanone. The journal of phvsical chemistrvA 2009, 113, 4198-207.

48. Guillaume, M.; Ruud, K.; Rizzo, A.; Monti, S.; Lin, Z.; Xu, X., Computational Study of the One- and Two-Photon Absorption and Circular Dichroism of (L)-Tryptophan. journal of physical chemistry. B 2010, 114, 6500-12.

49. Vesga, Y.; Hernandez, F. E., Study of the Effect of the Pulse-Width of the Excitation Source on the Two-Photon Absorption and Two-Photon Circular Dichroism Spectra of Biaryl Derivatives. J. Phys. Chem. A 2016.

50. Wu, F.; Zhang, G.; Tian, W.; Chen, W.; Zhao, G.; Cao, S.; Xie, W., Two-Photon Absorption and Two-Thoton Assisted Excited-State Absorption in $\mathrm{CdSe}_{0.3} \mathrm{~S}_{0.7}$ quantum dots. J. Opt. A-Pure Appl. Op. 2009, 11, 0652061-5.

51. Hernandez, F. E.; Belfield, K. D.; Cohanoschi, I.; Balu, M.; Schafer, K. J., Three- and FourPhoton Absorption of a Multiphoton Absorbing Fluorescent Probe. Appl. Opt. 2004, 43, 53945398. 
52. Leffler, J. E.; Grunwald, E., Rates and equilibria of organic reactions: as treated by statistical, thermodynamic and extrathermodynamic methods. Courier Corporation: 2013.

53. Pandith, A. H.; Islam, N., Electron Transport and Nonlinear Optical Properties of Substituted Aryldimesityl Boranes: a DFT Study. PloS one 2014, 9, e114125.

54. Hu, Z.; Khadka, V. S.; Wang, W.; Galipeau, D. W.; Yan, X., Theoretical Study of Twophoton Absorption Properties and Up-conversion Efficiency of New Symmetric Organic $\pi$ conjugated Molecules for Photovoltaic Devices. Journal of Molecular Modeling 2012, 18, 36573667.

55. Dalafi, H., Theoretical Investigation of Anomalies in 162 Er. Lettere Al Nuovo Cimento (1971-1985) 1978, 23, 247-249.

56. Cullity, B. D.; Graham, C. D., Introduction to Magnetic Materials. John Wiley \& Sons: 2011. 
TOC Graphic

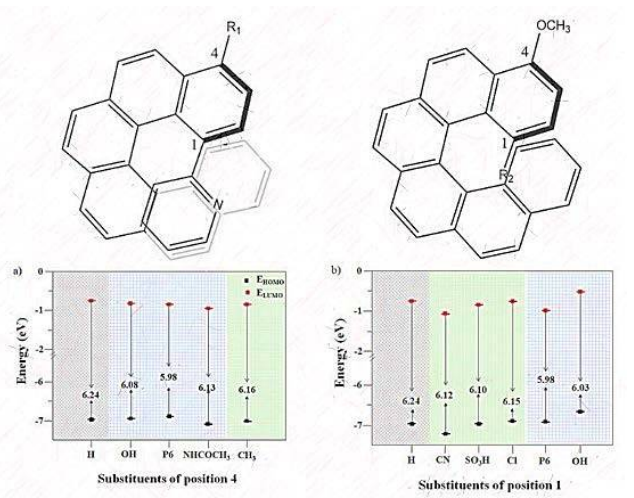



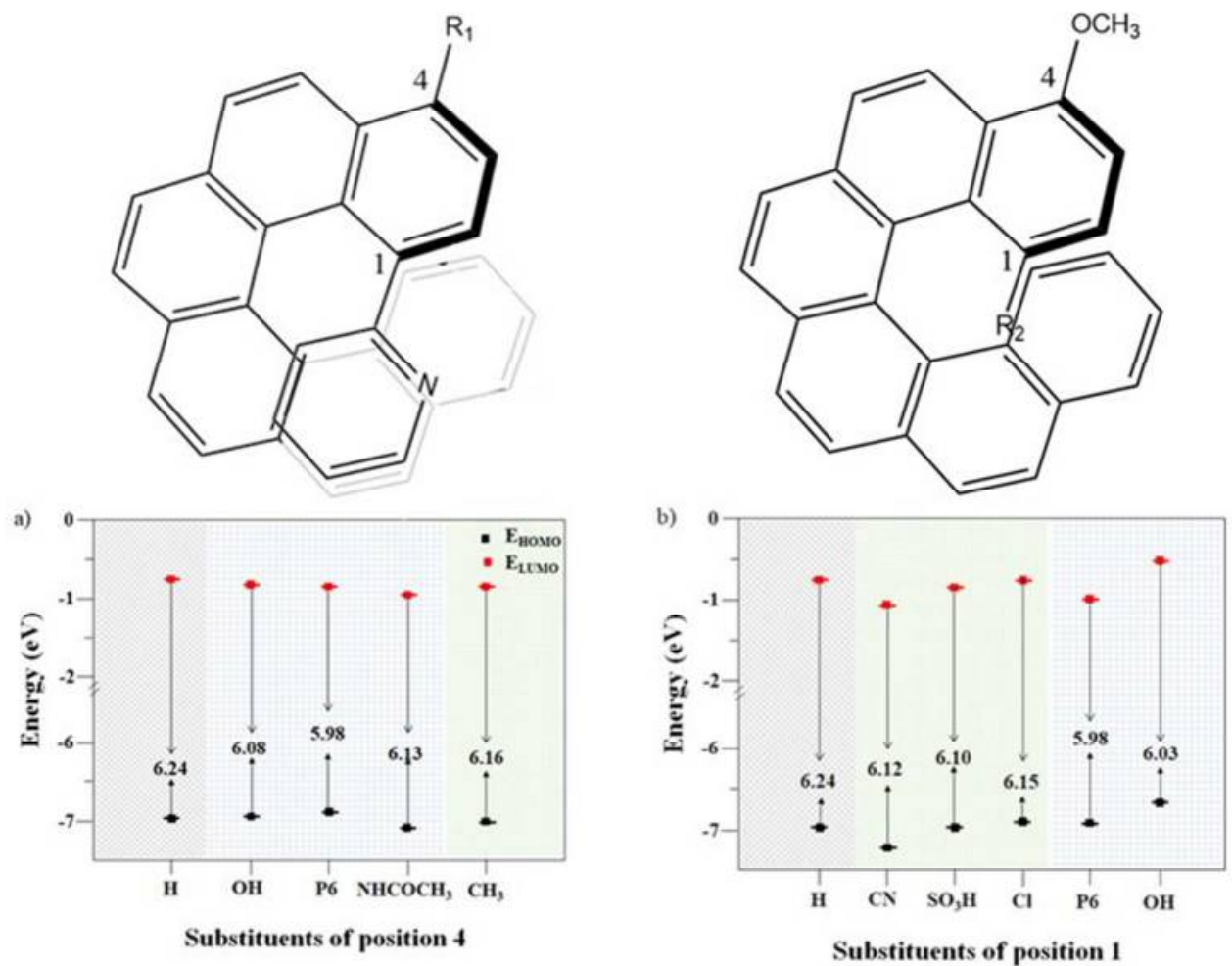

Effects of terminal push pull groups on the TPCD signal of Hexahelicene Derivatives.

$64 \times 50 \mathrm{~mm}(300 \times 300 \mathrm{DPI})$ 